\title{
Design of Electric Vehicle Charging Station in Macau
}

\author{
Tze Wood Ching
}

Department of Electromechanical Engineering, University of Macau, twching@umac.mo

\begin{abstract}
Electric vehicles (EVS) are clean due to their zero local emissions and low global emissions. They are also green due to their environmental friendliness, since electricity can be generated by renewable sources. Despite these obvious benefits, EVs have not been widely used around the world; the key reasons are due to their high price, short driving range or lack of charging facilities. With the growing concerns on price fluctuation, depletion of petroleum resources and global warming, there is fast growing interest in EVs in Macau. Thus, it is a pressing need for researchers and power utilities to develop various infrastructures for EV. This paper aims to present a time delay method for EV charging station, by shifting the night-time battery charging within the off-peak period, results are to fill in the valley of the system demand curve.
\end{abstract}

\section{Keywords}

charging stations, infrastructures, night-time charging, system demand leveling, travel model

\section{INTRODUCTION}

Battery powered electric vehicles (EVs) were one of the solutions proposed to tackle the energy crisis and global warming. However, the high initial cost, short driving range and long charging time have proved the limitation of battery powered EV [Chan, 2004; Chan, 2007]. The market of EVs remains in extremely limited extent by weight, lifetime and the constraint of cruising radius by one charge.

The daily energy consumption by an EV will be determined by the driving range/cycle and the charging time, while its impact on the electricity system demand will depend on the duration and pattern of charging. The electric utility's interest in EV lies in the anticipated and expected benefits beyond the simple increase in energy sales. It is expected that the EV charging load will be contained within system offpeak hours without affecting the peak demand, thus increasing the sale of low cost electricity. From the electric utility operation aspect, this potential to fill the valley [Wong et al., 2005] in the load curve will result in more electricity sales for the same system capacity [Rahman et al., 1993].

As a solution of a new peak brought by quick charge on electric demand, a diesel generation is a policy of peak demand generator for the time being, but which becomes a very expensive investment as the facility of countermeasures only for few peak hours. In some countries, it was considered that the EV battery to be one of the energy source when it is not moved. So it is very attractive to extract electricity from the EV battery, especially for private use, that can be seen not to be used around noon. The implementation of such vehicle-to-grid (V2G) technology depends on the communications support, interfaces for communication between the grid, charging points and EVs [Winkler et al., 2009].

In this paper, an EV charging station has been designed for both research and teaching purposes. The EV charging load will be programmed and shifted to fill the valley of the system load curve without regard to localized effects [Rahman et al., 1993].

The charging station was also proposed for management of an EV fleet of a local electric utility; with some modification to include a payment system for public use.

\section{GEOGRAPHIC INFORMATION OF MACAU}

Macau, also spelt as Macao, lies at the mouth of the

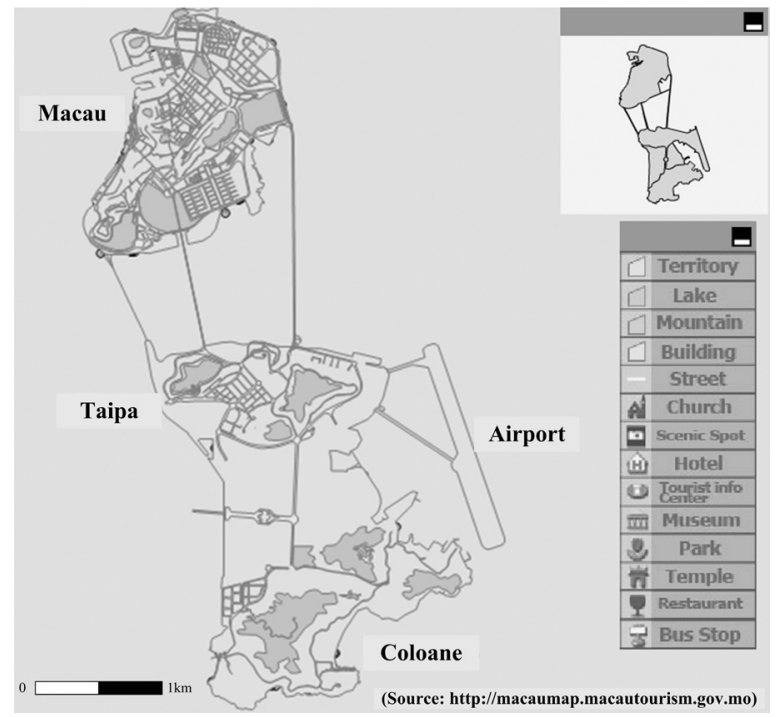

Fig. 1 Map of Macau

Source: http://macaumap.macautourism.gov.mo 
Table 1 Number of vehicles in Macau

\begin{tabular}{|c|c|c|c|c|}
\hline Year & Total & Light Vehicles & Heavy Vehicles & Motor Cycles \\
\hline 2007 & 174,520 & $76,117(43.6 \%)$ & $6,107(3.5 \%)$ & $92,296(52.9 \%)$ \\
\hline 2008 & 182,765 & $78,753(43.1 \%)$ & $6,288(3.4 \%)$ & $97,724(53.5 \%)$ \\
\hline 2009 & 189,350 & $80,499(42.5 \%)$ & $6,285(3.3 \%)$ & $102,566(54.2 \%)$ \\
\hline
\end{tabular}

Pearl River Delta of Guangdong Province, China, about $65 \mathrm{~km}$ west of Hong Kong. The Territory consists of Macao peninsula, and two islands-Taipa and Coloane as shown in Figure 1. Colonized by Portugal in the 16th century, the Portuguese and the Chinese have cultivated in the city a unique blend of the two cultures. On 20 December 1999, Macau was returned to China and is known as Macao Special Administrative Region (Macao SAR).

Information from the Statistics and Census Service [Environment Statistics, 2008] indicated that total land area of Macao measured $29.2 \mathrm{~km}^{2}$ as at the end of 2008, with the total population of 549,200, with 95 $\%$ of its population being Chinese, and the rest were Portuguese, Europeans and others.

Total length of public roads in Macau was $404.4 \mathrm{~km}$, and the motor vehicle density was 452 vehicles per kilometer.

From Table 1, the total number of motorcycles is steadily increasing, with 102,566 licensed by the end of $2009,54.2 \%$ of total number of vehicles in Macau.

With the growing concerns on price fluctuation and depletion of petroleum resources and global warming, there is fast growing interest in EVs in Macau. Air pollution is also another important concern. If this fossil-fuel trend continues from conventional cars, the sky will become permanently gray [Chan et al., 2009]. Thus, it is a pressing need for researchers and power utilities to develop various infrastructures for $\mathrm{EV}$, while the electric utility's interest in EVs lies in the anticipated and expected benefits of increase in energy sales, and the EV charging loads will be contained within system off-peak hours without affecting the peak demand. A sizable EV load can introduce a new peak in the early off-peak period. It may have scheduling implications, and completely throw any load management programs off balance [Rahman et al., 1993], if they are not properly programmed/shifted.

This paper focus on the development of charging facilities for the possible market of EVs in the Macau area [Ching, 2010], the proposed charging stations are particularly suitable for both business users and electric utility.

\section{DESIGN OF EV CHARGING STATIONS FOR MACAU}

The impact of EV loads on the energy demand is determined not only by the number of EV in use and their usage pattern, but also by the number of EV being charged at any instant and the charging profile of the battery module. It would be logical to charge an EV only during the off-peak hours so as to fill up the valley in the system load curve; it may not always be feasible. The following factors were studied to facilitate the design of the charging station:

- The load curve of local electric utility;

- The electricity tariff structure;

- The travel model of vehicle users;

- The typical battery charging curves (electric motorcycles were chosen for this project).

\subsection{Electricity demand curve and tariff}

A load diagram of a local electric utility is shown in Figure 2, while the electricity tariff structure is tabulated in Table 2. From Figure 2, the system load decreases after 20:00 hours until 08:00 hours of the following day. The power company defined the offpeak period from 20:00 hours to 09:00 hours of next morning as shown in Table 3, according to the recorded load curve in Figure 2.

From the utility's point of view, the EV battery charging should proceed within the off-peak hours, in order not to increase the system demand and the installed generation, transmission and distribution facilities,

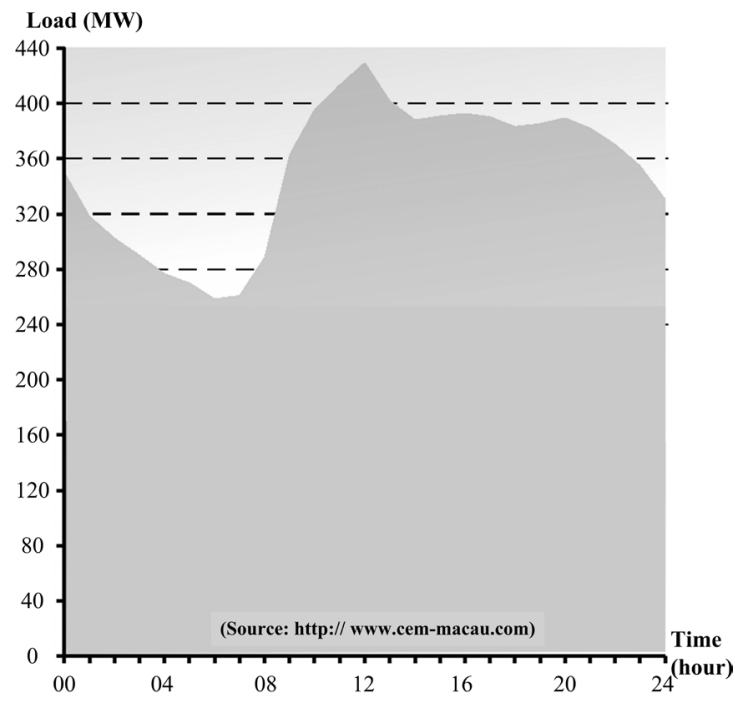

Fig. 2 Typical daily load curve 
Table 2 Electricity charge

\begin{tabular}{|l|l|l|}
\hline Demand & & $\$ 21.484$ per kW \\
\hline \multirow{2}{*}{ Active Power } & Peak hours & $\$ 0.874$ per kWh \\
\cline { 2 - 3 } & Off-peak hours & $\$ 0.767$ per kWh \\
\hline \multirow{2}{*}{ Reactive Power } & Peak hours & $\$ 0.348$ per kVARh \\
\cline { 2 - 3 } & Off-peak hours & \$0.116 per kVARh \\
\hline
\end{tabular}

Note: Demand - $\mathrm{kW}$ calculated by $0.2 \mathrm{Pc}+0.8 \mathrm{Pu}$

$\mathrm{P}_{\mathrm{u}}$ : highest measured demand in $\mathrm{kW}$ during the billing period $\mathrm{P}_{\mathrm{c}}$ : subscribed demand in $\mathrm{kW}$

and they are sufficient to cater for those additional EV charging loads. As a user, it would also be more economical to charge their EVs during the night-time with a comparatively lower power charges as depicted in Table 2.

\subsection{Driving pattern in Macau area}

Motorcycles are not only widely used in by private users but also business users, more than half (54.2\%) of licensed vehicles in Macau are motorcycles $(102,556$ recorded at the end of 2009). It is straightforward to broaden the EV market by first choosing electric motorcycles.

The travel patterns of different types of motorcycle user were schematically shown in Figure 3, and nightcharge periods were imposed on the same diagram when an EV is employed. In Figure 3, charging would happen at any instant if not properly organized. Furthermore, V2G was not suitable for Macau since most private vehicle users would travel during lunch hours.

Table 3 Electricity tariff periods

\begin{tabular}{|l|l|}
\hline Peak hours & 09:00 to 20:00 \\
\hline Off-peak hours & $00: 00$ to $09: 00 ; 20: 00$ to 24:00 \\
\hline
\end{tabular}

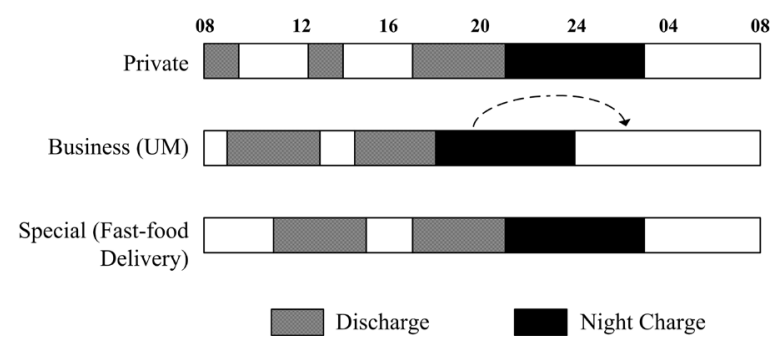

Fig. 3 Travel model of different types of vehicles

Table 4 Typical cruising ranges

\begin{tabular}{|l|l|}
\hline Private & $8 \mathrm{~km}$ \\
\hline Business (University) & $20 \mathrm{~km}$ \\
\hline Special (e.g. Fast-food delivery) & $40 \mathrm{~km}$ \\
\hline
\end{tabular}

The average cruising range in Macau area was also summarized in Table 4.

If no additional measures to manage the charging loads, the EV charging loads would create an additional burden to the generation, transmission and distribution facilities. The major purpose of this project is to delay the EV charging loads to after 20:00 hours and contain them within the off-peak period defined by the power company.

\subsection{Electricity demand by night-charge}

The characteristics of a typical electric motorcycle being studied were tabulated in Table 5, with a battery charging rate (temporal variation of the charging load per unit of recharging energy) shown in Figure 4.

As shown in Table 5, the maximum range per one night-charge was $45 \mathrm{~km}$, which was greater than the average cruising range of most users in Macau, so one night-charge was sufficient to fully charge a motorcycle for all general users. A battery charging characteristic of the motorcycle being studied was shown in Figure 4, the time for a full charge is about 6 hours.

Table 5 Properties of electric motorcycle

\begin{tabular}{|l|l|}
\hline Vehicle type & Scooter \\
\hline Motor type & Brushless a.c. \\
\hline Rated power & $0.6 \mathrm{~kW}$ \\
\hline Maximum power & $1.2 \mathrm{~kW}$ \\
\hline Battery type & Lithium- ion \\
\hline Battery voltage/capacity & $25 \mathrm{~V} / 14$ Ah \\
\hline Charging time & $\sim 4$ hours $(90 \%) /$ \\
\hline Range (Fully charged) & 45 km \\
\hline
\end{tabular}

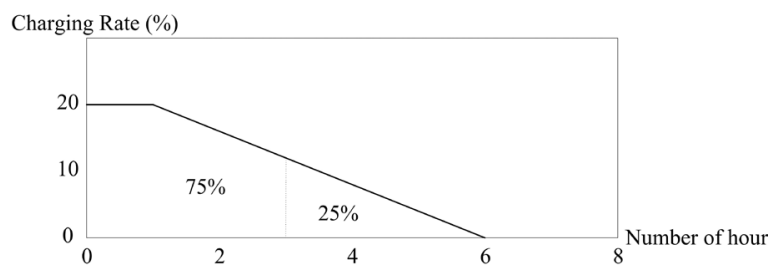

Fig. 4 Battery charging characteristic (6-hr charge)

\subsection{Shifting of charging loads}

In Table 3, the off-peak period defined by the power utility was between 20:00 hours in the evening to 09:00 hours in the next morning, the total duration of off-peak period was 13 hours. From the measured charging current shown in Figure 4, $75 \%$ of the battery would be charged within 3 hours. It is proposed to divide the EV loads into different groups, and the 
start-time between groups would be separated by 2 to 3 hours.

The anticipated charging currents were simulated with different combinations of group/separating hour. Results were shown in Figure 5.

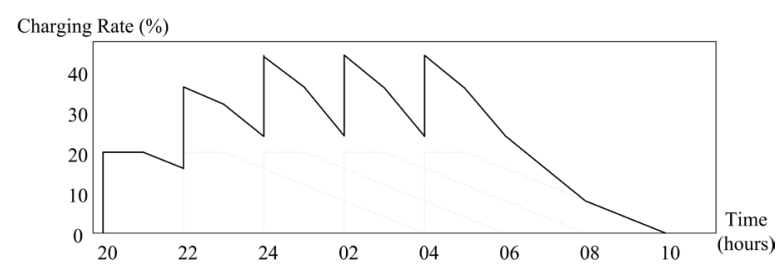

(a)

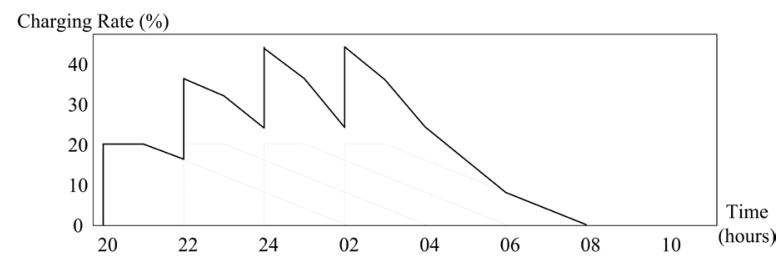

(b)

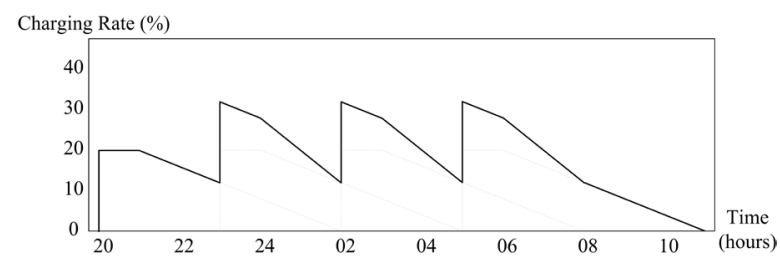

(c)

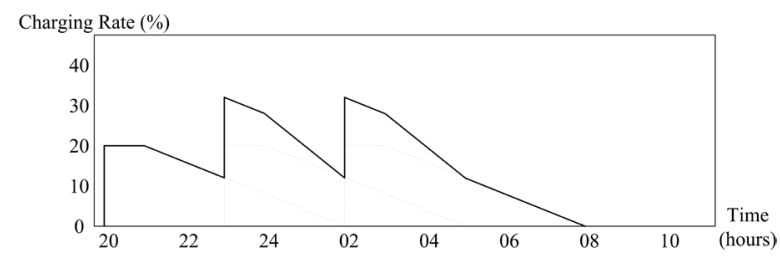

(d)

Fig. 5 Simulated charging characteristics for different combination of groups/separating hours: (a) $5 / 2$; (b) 4/2; (c) 4/3; and (d) 3/3

\section{DESIGN AND IMPLEMENTATION OF EV CHARGING STATION IN MACAU}

The charging station at University of Macau (UM) is primarily intended to demonstrate the practical implementation of theoretical approaches mentioned in previous section of this paper and to serve as a teaching tool for academic programs. The overall structure was shown in Figure 6 to 7.

The charging station was a system for connecting EVs to the power grid for charging (refueling). The hardware and software concept covers user authentication, management, measurement and fleet administration.

The whole system were implemented with an industrial PC, proximity card reader was used for validating and recording activities of both drivers and vehicles.
When checking-out an EV, drivers were required to use their staff card for validation with PIN. Both staff card and vehicle card were required for checking-in an EV, car-park number and odometer readings were also required. Numeric keys on the touch-screen have been integrated as an input/output interface for drivers and facilitate intuitive operation of the charging station. An intelligent energy meter was installed to monitor the electric power consumption and other relevant electrical parameters such as power quality performances; the control features of the energy meter were also used for initiating delayed charging at preprogrammed time intervals.

At present the station was designed to fuel a fleet of 9 EVs for UM, with their charging start-time divided into 3 groups, with starting times at 20:00, 23:00 and 02:00 hours respectively, according to scenario (d) in Figure 5. When more EVs were to be adopted, the charging loads in Figure 5 (b) with 4 groups separated by 2 hours would still be absorbed by the demand curve without additional burden on the maximum demand.

Since not all EVs were fully discharged when returned, the system was also designed to record the odometer readings and an intelligent energy meter was installed to record their respective charging profiles. Data collected would be utilized to determine the grouping combinations for delayed charging in the future. If the travel distance of any EV returned (during lunch break) was greater than the $70 \%$ of its maximum cruising range, the charging station was programmed to start charging immediately. Proximity cards and reader were for administration and identification purposes, and would be implemented as payment system when the charging station was open for general public. Moreover, electrical safety, charging, measurement and protection systems were designed according to current standards (IEC 61851-1, BS EN 61851-21, BS EN 61851-22, BS EN 62196-1).

\section{CONCLUSION}

An EV charging station was designed and implemented for connecting EVs to the electric power grid for charging. The proposed system not only provided the fleet administration and load management features, but also shift/delay the battery charging period within the utility's defined off-peak period, conveniently filled the valley in the system load curve without regard to localized effects.

\section{Acknowledgements}

The author gratefully acknowledges Mr. Leo Iong for his contributions on this study. This paper was supported by the Research Council of the University of 


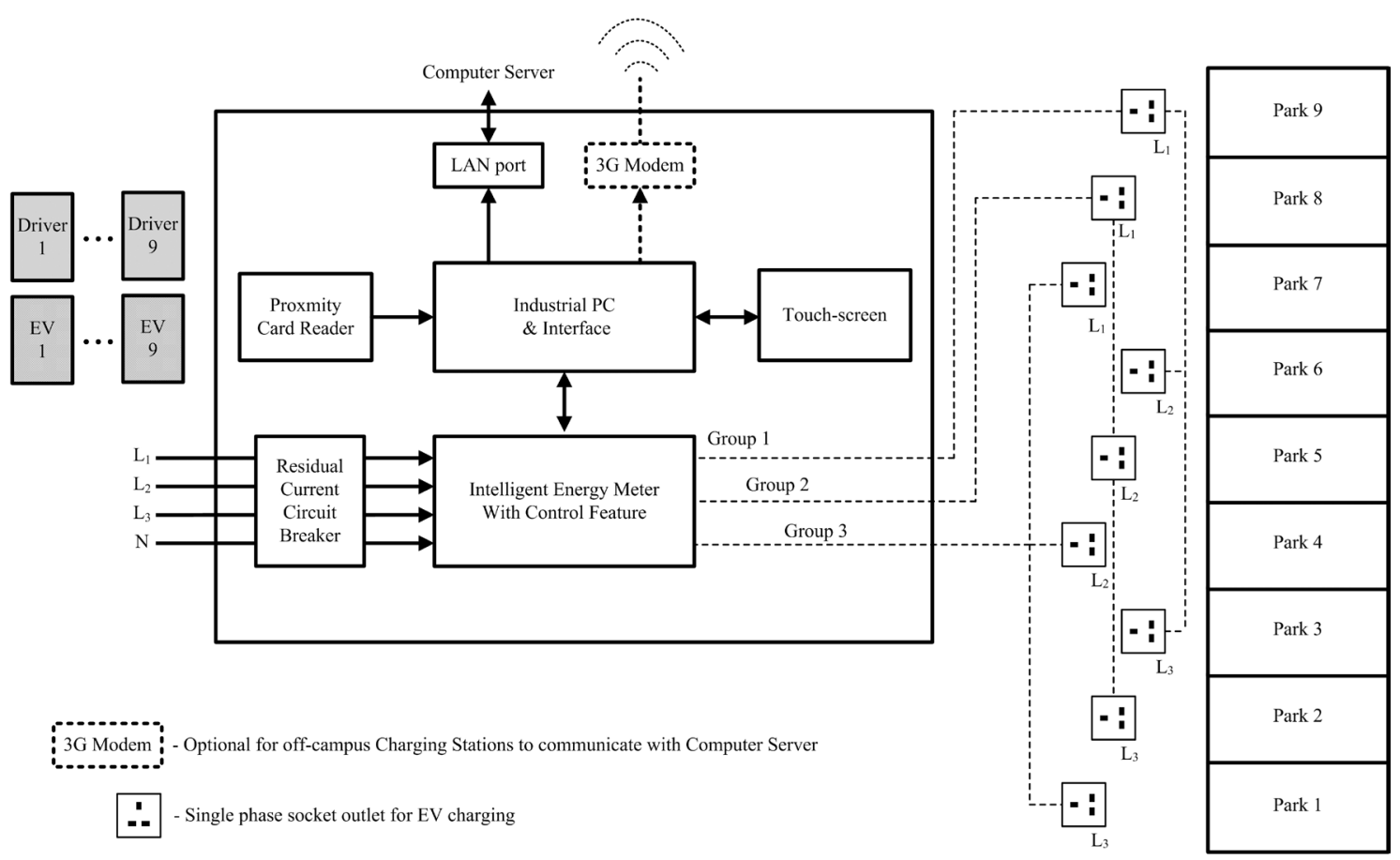

Fig. 6 Schematic of the EV charging station

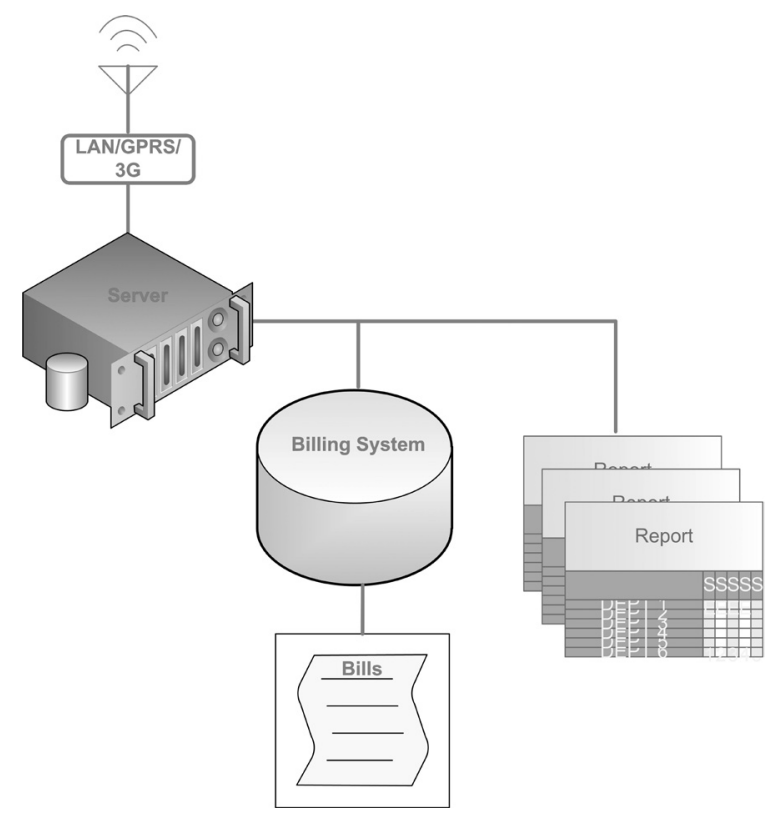

Fig. 7 Schematic of the computer server, billing \& reporting system

Macau under CG160/09-10S/CTW/FST.

\section{References}

Chan, C. C., The state of the art of electric vehicles, Journal of Asian Electric Vehicles, Vol. 2, No. 2, 579-600, 2004.

Chan, C. C., The state of the art of electric, hybrid, and fuel cell vehicles, Proceedings of the IEEE,
Vol. 95, No. 4, 704-708, 2007.

Chan, C. C., Y. S. Wong, A. Bouscayrol, and K. Chen, Powering sustainable mobility: Roadmaps of electric, hybrid, and fuel cell vehicles, Proceedings of the IEEE, Vol. 97, No. 4, 603-607, 2009.

CENELEC, Electric vehicle conductive charging system-Part 1: General requirements, IEC 61851$1: 2001,2001$.

CENELEC, Electric vehicle conductive charging system-Part 21: Electric vehicle requirements for conductive connection to an a.c/d.c. supply, BS EN 61851-21:2002, 2002.

CENELEC, Electric vehicle conductive charging system-Part 22: AC electric vehicle charging station, BS EN 61851-22:2002, 2002.

CENELEC, Plugs, socket-outlets, vehicle couplers and vehicle inlets - Conductive charging of electric vehicles_-Part 1: Charging of electric vehicles up to $250 \mathrm{~A}$ a.c. and $400 \mathrm{~A}$ d.c., BS EN 62196-1:2003, 2004.

Ching, T. W., Electric vehicle charging stations in Macau, The 25th World Battery, Hybrid and Fuel Cell Electric Vehicle Symposium \& Exhibition, CDRom, 2010.

Macau Government, Environment statistics 2009, dsec.gov.mo/Statistic.aspx?lang=en-US, 2009.

Rahman, S., and G. B. Shrestha, An investigation into the impact of electric vehicle load on the electric utility distribution system, IEEE Transactions on Power Delivery, Vol. 8, No. 2, 591-597, 1993. 
Winkler, T., P. Komarnicki, G. Mueller, G. Heideck, M. Heuer, and Z. A. Styczynski, Electric vehicle charging stations in magdeburg, IEEE Vehicle Power and Propulsion Conference, 60-65, 2009.

Wong, Y. S., K. T. Chau, and C. C. Chan, Load forecasting of hybrid electric vehicles under real time pricing, Journal of Asian Electric Vehicles, Vol. 3, No. 2, 815-818, 2005.

(Received December 2, 2010; accepted January 10, 2011) 